\title{
CONSIDERAÇÕES DA PSICOLOGIA HOSPITALAR SOBRE A ENTREVISTA FAMILIAR NA DOAÇÃO DE ÓRGÃOS E TECIDOS
}

Considerations on health psychology upon family interview for organ and tissue donation

\author{
Carla Bono Olenscki Coelho', Dnyelle Souza Silva²
}

\section{RESUMO}

Apesar da legislação e das equipes de captação e doação de órgãos serem compostas por multiprofissionais, o papel do psicólogo dentro dessas equipes não tem sido relatado na literatura. Objetivo: levantar através de uma pesquisa bibliográfica os aspectos psicológicos presentes no contexto da doação de órgãos e de que forma o psicólogo pode atuar no processo da abordagem familiar. Métodos: o presente estudo trata de uma pesquisa de investigação do acervo bibliográfico no período de 1997 a 2012, a partir dos descritores: doação e captação de órgãos e tecidos, psicologia hospitalar, bioética, morte, luto e unidade de terapia intensiva. Os estudos encontrados foram categorizados em três subitens: psicologia hospitalar, processo de doação de órgãos e aspectos psicológicos envolvidos na doação que repercutem na abordagem familiar. Conclusão: A psicologia hospitalar tem no seu percurso teórico e prático amplas condições de oferecer suporte ao psicólogo que visa sua inserção nos serviços de captação e doação de órgãos, principalmente, quando sua atuação estiver focada no acolhimento e abordagem familiar, e nos aspectos subjetivos do processo.

Descritores: Psicologia em Saúde; Obtenção de Tecidos e Órgãos; Entrevista; Bioética; Morte Encefálica; Morte; Unidades de Terapia Intensiva

\begin{abstract}
Instituição:
${ }^{1}$ Serviço de Psicologia Hospitalar do Hospital Geral Público de Palmas Palmas/TO.

2 Serviço de Psicologia do Programa de Transplantes do Hospital Israelita Albert Einstein - São Paulo/SP
\end{abstract}

Correspondência:

Carla Bono Olenscki Coelho

Hospital Geral Público de Palmas

201 SUL NS 01 Conjunto 02 Lote 01- CEP:77.015-202 - Palmas/TO

Tel.: (63) 9214-4922

e-mail:ca_olenscki@yahoo.com.br

\section{INTRODUÇÃO}

De acordo com Simonetti, a Psicologia Hospitalar tem como campo a leitura da subjetividade dentro dos hospitais gerais e de especialidades. Em outras palavras, enfatiza que toda doença e toda hospitalização apresentam aspectos psicológicos tanto no paciente quanto nas famílias e equipes de saúde. ${ }^{1}$

Para que haja a doação, faz-se necessária a abordagem da família, cujo objetivo é o oferecimento da oportunidade de doar os órgãos e tecidos do ente falecido, momento em que a família encontra-se em extremo sofrimento psíquico. ${ }^{2}$

A intervenção do psicólogo em momentos de crise é de grande valia para que a família enlutada possa vivenciar esse momento da forma mais saudável psiquicamente. O psicólogo dentro do hospital posiciona-se como membro de ligação da tríade paciente, família e equipe, sendo o interlocutor das necessidades e desejos do paciente e seus familiares, propiciando melhoria na qualidade do atendimento dos profissionais e da instituição e favorecendo dessa forma a decisão pela doação de órgãos. ${ }^{3}$ 
O presente artigo percorre a literatura em busca de instrumentos para compreender de que modo a inserção do psicólogo nos serviços de captação e doação de órgãos pode colaborar para a melhoria da assistência prestada às famílias enlutadas. Estender-se-á nos aspectos psicológicos do processo de doação de órgãos sólidos e nos procedimentos interdisciplinares de assistência hospitalar, perfazendo a legislação brasileira sobre doação, captação e transplante de órgãos e tecidos.

\section{OBJETIVOS}

1- Levantar estudos que abordam o papel do psicólogo hospitalar nas equipes de captação e doação de órgãos;

2 - Buscar na literatura os aspectos psicológicos da doação de órgãos.

\section{MÉTODOS}

O presente estudo trata de uma pesquisa de revisão bibliográfica, através da investigação do acervo bibliográfico no período de 1997 a 2012 e a partir dos descritores: doação e captação de órgãos e tecidos, psicologia em saúde, bioética, morte, morte encefálica e unidades de terapia intensiva. Foram utilizados artigos de revisão, pesquisa de campo, legislações, pesquisas de opinião/editorial, retirados das bases de dados: Scientific Eletronic Library Online (SciELO), Literatura Latino Americana e do Caribe em Ciências da Saúde (LILACS), PubMed, capítulos de livros, periódicos, sites oficiais do Ministério da Saúde, Conselho Federal de Medicina, Conselho Federal de Psicologia.

\section{RESULTADOS}

Foram encontrados 34 artigos a partir dos descritores anteriormente citados, e foram categorizados em subitens de forma didática dos temas prevalentes na literatura, conforme segue:

\section{A psicologia hospitalar: contribuições a respeito do luto,} do processo de morte e adoecimento

A Psicologia Hospitalar é uma especialidade recente; sua regulamentação deu-se a partir da Resolução no 02/2001 do Conselho Federal de Psicologia, que institui o título profissional de especialista em psicologia hospitalar. Dentre suas atribuições, compete ao psicólogo intervir nas repercussões emocionais advindas das diversas relações existentes no contexto do adoecer e da hospitalização entre paciente, família e equipe de saúde, e participar e assessorar a equipe interdisciplinar quanto à tomada de decisões referente às condutas adotadas, a fim de promover apoio e segurança ao paciente e à família. ${ }^{4}$ Vale ressaltar que a Psicologia Hospitalar é encontrada apenas no Brasil; em outros países é denominada Psicologia da Saúde, tendo sua prática voltada para as intervenções nos níveis primário, secundário e terciário. A atuação do psicólogo hospitalar limita-se aos níveis secundários e terciários nos quais a doença já está instalada. O psicólogo que atua em instituições hospitalares desenvolve habilidades nas seguintes áreas: clínica, de pesquisa e de administração de programas de saúde. ${ }^{5}$

A tríade da psicologia hospitalar está pautada na humanização do atendimento. De um lado, os pacientes e familiares clamam por apoio, compreensão e suporte para o enfrentamento do momento de crise - do adoecer e da iminência do morrer. Por outro lado, as equipes de saúde, convivem cotidianamente com a morte, causando-lhes elevado grau de stress e de adoecimento mental. As estratégias de atuação são diversas, mas a essência do trabalho está em decodificar as relações e sentimentos vivenciados no contexto hospitalar, sendo o porta voz do sofrimento humano, visando a sua diminuição e assegurando o bem-estar físico, mental e social. ${ }^{6}$

A morte, apesar da dura realidade dentro do contexto hospitalar, propicia inúmeras possibilidades de intervenções psicológicas, onde o morrer pode ser vivenciado de forma mais tranquila, elaborada e humana, conforme descreve artigo sobre alguns objetivos das intervenções psicológicas na terminalidade:

\begin{abstract}
"[...] oferecer suporte emocional ao doente e à sua família em situação de comunicação de prognóstico grave; facilitar $e$ estimular a comunicação entre os familiares e a equipe profissional, utilizando termos e informações francas e factuais; [...] reconhecer e encorajar a família a utilizar suas crenças e rituais perante a morte; auxiliar na melhoria da qualidade de vida do enfermo na iminência da morte e de sua família, priorizando a minimização do sofrimento e da dor sobre a cura da doença, juntamente com a vivência do luto antecipatório".
\end{abstract}

O binômio paciente-família é indissociável e o processo do morrer desestabiliza todo o núcleo familiar, instalando um momento de crise e interrupção, e o psicólogo tem a possibilidade de favorecer a elaboração das fantasias, inseguranças, temores e angústias por meio de sessões de psicoterapia focal e de luto antecipatório, assim como propiciar a aproximação com a equipe de saúde para sanar as dúvidas e ansiedades. ${ }^{8}$

\section{O processo de doação e captação de órgãos}

O processo de doação-transplante é entendido como o conjunto de ações e procedimentos que conseguem transformar um potencial doador em doador efetivo, concluindo o processo com o transplante. O transplante de órgãos e tecidos é o último recurso terapêutico para determinadas doenças crônicas irreversíveis. ${ }^{9}$

A legislação brasileira sobre doação, captação e transplante de órgãos e tecidos também é recente. Entrou em vigor em 02/1997 por meio da Lei Federal no 9.434, que dispõe sobre a "remoção de órgãos, tecidos e partes do corpo humano para fins de transplante e tratamento e dá outras providências". ${ }^{10} \mathrm{O}$ Decreto ${ }^{\circ} 2.268$ de 06/1997, regulamenta a Lei no 9.434/97, na qual a doação era presumida, conforme Art. 14 - "a retirada de tecidos, órgãos e partes, após a morte poderá ser efetuada independentemente de consentimento da família se, em vida, o falecido a isso não tiver manifestado sua objeção". Nesse caso, o cidadão necessitava manifestar sua vontade contrária à doação em documentos de Identificação Civil ou na Carteira Nacional de Habilitação, mediante inserção da expressão: "Não doador de órgãos e tecidos". ${ }^{11}$ 
Problemas de ordem ética, como o desrespeito à autonomia e questões de desigualdades socioculturais, onde muitos não tinham acesso aos meios de comunicação e divulgação, ${ }^{12}$ fizeram com que os dispositivos legais fossem modificados em 2001 por meio da Lei $n^{\circ} 10.211$, estabelecendo o consentimento informado a um familiar ou cônjuge, desde que se obedeça a linha sucessória, reta ou colateral, até o segundo grau para consentimento (pais, filhos, irmãos, netos e avós). ${ }^{13}$

Compreende-se por potencialdoador de órgãos, aquele paciente que se encontra em coma Glasgow 3 e de etiologia conhecida. De acordo com o Registro Brasileiro de Transplantes, em 2012, o acidente vascular cerebral correspondeu a $46 \%$ das notificações de $\mathrm{ME}$, seguido de traumatismo crânio encefálico (40\%). ${ }^{14}$ A partir da identificação, abre-se o protocolo de diagnóstico de ME pela equipe da UTI através da realização de dois exames clínicos e um exame complementar para potenciais doadores acima de dois anos. Nesse momento, a família deverá ser comunicada, acolhida, e poderá convidar um médico de confiança da família para acompanhar todo o processo diagnóstico. O CFM publicou em 08/1997 a Resolução 1.480 deliberando que ME é a cessação irreversível das funções neurológicas, dos hemisférios cerebrais e tronco encefálico. A ME é morte, e, em 2007 o CFM dispôs em resolução que é legal e ética a suspensão dos procedimentos de suportes terapêuticos após o diagnóstico, mesmo que o paciente não seja doador. No atestado de óbito deverá constar o horário de término do protocolo. Toda ME deverá ser notificada e comunicada à família e à Central de Notificação, Captação e Distribuição de Órgãos (CNCDO). ${ }^{2,9,15-17}$

Após confirmação diagnóstica, realiza-se a entrevista familiar por equipe multiprofissional especializada, que não deve ter vínculo assistencial anterior com a família. ${ }^{2}$ Para tal função, criaram-se as Comissões Intra-hospitalares de Doação de Órgãos e Tecidos para Transplante (CIHDOTTs) e as Organizações de Procura de Órgãos (OPO), que, dentre outras atribuições, englobam também: identificar potenciais doadores, viabilizar o diagnóstico de $\mathrm{ME}$, promover e organizar o acolhimento às famílias, responsabilizar-se pela educação permanente sobre acolhimento familiar e demais aspectos do processo de doação e transplante, implementar programas de qualidade e boas práticas relativas ao processo de doação e transplante. ${ }^{18,19}$

Segundo o Registro Brasileiro de Transplantes (2012), foram notificados 8.025 potenciais doadores, dentre os quais, 2.406 tornaram-se doadores efetivos. Foram realizadas 5.598 entrevistas familiares, dentre as quais, 2.315 (41\%) recusaram a doação. ${ }^{14}$ Estudos têm sido direcionados a responder o porquê das recusas familiares ainda serem prevalentes no nosso meio.

\section{Aspectos psicológicos envolvidos na doação de órgãos e na entrevista familiar}

A entrevista familiar deve ser realizada por equipe capacitada em conduzir o processo de abordagem de forma ética e humana, a fim de sensibilizar e resgatar a história de vida e de adoecimento do potencial doador, orientar, reconhecer e auxiliar nas fases de elaboração do luto. ${ }^{20}$
Para que a comunicação seja efetiva, deve-se assegurar o fornecimento de informações, garantia da compreensão, a voluntariedade e o consentimento. E durante todo o processo, a aplicação dos princípios da bioética: autonomia, beneficência, não maleficência e justiça, precisam ser respeitadas. ${ }^{12}$

"É importante que o entrevistador seja empático e respeitoso com a família atendendo a suas necessidades e angústias, amenizando os sentimentos de culpa, lembrando-se sempre de que a atenção que é dispensada à família naquele momento de dor é uma deferência e não uma obrigação". ${ }^{2}$

Alguns autores sugerem que a habilidade do solicitante pode diminuir a recusa no processo de doação e que a abordagem social e observância ético-legal aumentam a segurança e confiabilidade no processo de doação. ${ }^{21-23}$

É fundamental a avaliação do estado emocional dos familiares a fim de identificar a capacidade de ouvir e compreender as informações prestadas pela equipe, assim como é de extrema importância saber reconhecer o momento mais adequado para a abordagem. ${ }^{23-25} \mathrm{~A}$ discussão prematura sobre a doação pode resultar na diminuição da aceitação da família, devido ao não entendimento do processo e por gerar sentimentos de indignação e insensibilidade perante a situação vivida. É necessário dar tempo suficiente para que a família internalize e elabore todas as informações repassadas. O momento da assinatura do consentimento exarceba a dor da perda e coloca a família novamente em contato com a realidade traumática, e o apoio psicológico deve ser oferecido naquele momento. ${ }^{26}$

Os familiares que se encontram na negação da morte estão mais suscetíveis a recusarem a doação, mesmo tendo conhecimento do desejo prévio de doar por parte do potencial doador. Quanto mais jovem o potencial doador, mais difícil se torna a aceitação da morte, assim como nas mortes violentas e traumáticas; os casos de morte por suicídio geram na família sentimento de culpa, e a doação surge como mecanismo de defesa; as famílias mais indagadoras sugerem melhor organização para tomada de decisões; quando a decisão é tomada em conjunto e racionalmente, há uma tendência favorável à aceitação se comparada quando a tomada de decisão é impulsiva e logo após a abordagem; o conhecimento prévio da intenção de doar pode amenizar a ambiguidade da decisão. ${ }^{20}$

Outro aspecto subjetivo relevante é o significado de $\mathrm{ME}$, que deveria ser mais bem difundido na população, como mostrou estudo acerca da influência do conhecimento sobre ME e a intenção de doar, no qual a maioria dos participantes é favorável à doação, porém a insegurança e desconhecimento quanto a ME foi apontado pela grande maioria como fatores que impedem a doação, devido aos pensamentos e fantasias encontrados, como por exemplo: o médico pode estar equivocado e o paciente vivo. ${ }^{9}$

$\mathrm{O}$ risco de sobreviver com danos cerebrais parece ser a maior preocupação para alguns familiares do que o medo da morte. Para alguns indivíduos, o diagnóstico de ME e a ligação com dano cerebral representa a perda irreversível da vida mental, mas não propriamente a morte. $\mathrm{O}$ paradoxo da comunicação da morte com a presença de respiração e batimentos cardíacos parece ser o gatilho para conflitos emocionais e cognitivos que os familiares enfrentam. ${ }^{27}$ 
Estudo realizado em São José do Rio Preto aponta que quase toda a população pesquisada ouviu falar sobre transplante de órgãos e sabia da existência de programa de captação e doação de órgãos; a grande maioria concordou com a retirada de órgãos em casos de morte de parentes; e quanto às pessoas que não concordaram com a doação, o principal motivo estava relacionado às dúvidas quanto ao diagnóstico de ME; para quase metade dos entrevistados, o diagnóstico de ME deveria ser informado por um médico e $25 \%$ afirmaram que a presença do psicológo seria importante no momento da comunicação. ${ }^{28}$

O principal motivo da recusa familiar é o desejo de não ser doador por parte do falecido, conforme aponta um estudo multicêntrico realizado nos EUA. ${ }^{29}$ Outra variável importante é o baixo nível educacional, que pode dificultar a compreensão do processo de doação, e os meios de comunicação também podem exercer influência sobre a opinião pública, assim como a cultura de um determinado povo. Por essas razões, os profissionais envolvidos na doação têm o dever de esclarecer todas as dúvidas detalhadamente, acerca de todo o processo de doação. ${ }^{30}$ As crenças podem também interferir na decisão de doar, tais como: crenças religiosas, culturais, educacionais, altruísticas e normativas. As crenças religiosas são uma barreira importante, particularmente para testemunhas de Jeová e judeus ortodoxos. ${ }^{31}$

Em outros estudos, o altruísmo e a participação de toda a família favoreceu a tomada de decisão, seguida do conhecimento da vontade do doador em vida. A análise de sentimentos, comportamentos, crenças e valores dos familiares antes da entrevista familiar pelos profissionais da saúde ajudam no entendimento sobre ME e a aceitação do processo de doação. ${ }^{23,26,32}$

$\mathrm{Na}$ Espanha e no Brasil, estudos apontam variáveis importantes sobre a decisão de doar ou não os órgãos de familiares falecidos, como: respeito aos doadores, manifestação em vida sobre a vontade de doar, grau de escolaridade e preocupação sobre possíveis irregularidades no processo de doação, influência sobre aspectos estéticos do cadáver, relação com a unidade hospitalar e as informações repassadas pelos médicos à família.
Concluiu-se que os familiares de doadores são mais favoráveis à doação no futuro do que as famílias de não doadores. Algumas famílias manifestam o ato de doar como um ato de solidariedade, entendida como um ato voluntário, como reciprocidade, sentimentos de conforto ao pensar que poderiam encontrar-se numa situação semelhante e que outros poderiam ajudá-las, além da valorização social. ${ }^{20,33,34}$

\section{CONCLUSÃO}

Os estudos acerca do processo de doação de órgãos e abordagem familiar direcionam para aspectos nos quais a psicologia hospitalar desenvolve sua formação prática e teórica, conduzindo cada vez mais para a necessidade de inserção do psicólogo nesse contex to e auxílio na atenção à subjetividade inerente a esse processo.

A doação de órgãos é um processo multifatorial, permeado por variáveis biopsicossociais como: crenças, modos de enfrentamento do luto, compreensão da morte, e a família parece ser o principal mediador para o sucesso da captação.

Considerando o psicólogo hospitalar o profissional responsável pela leitura da subjetividade e compreensão do processo de enfrentamento da perda, pensar nas possibilidades da sua atuação nas equipes de captação de órgãos permite vislumbrar o alcance de melhorias para a escuta, acolhimento e humanização do processo.

Este estudo almeja uma intervenção diretiva no âmbito da prática do psicólogo hospitalar e sua inserção no contexto da doação de órgãos através da vivência e sentimentos das famílias envolvidas no processo de morte encefálica e luto, ofertando suporte profissional e institucional às equipes de captação e doação de órgãos. Para que a prática seja consolidada, estudos mais abrangentes se tornam necessários.

\section{AGRADECIMENTOS}

Agradeço ao Hospital Geral Público de Palmas, onde atuo na área de psicologia hospitalar, que serve de estímulo para a implementação e consolidação do serviço de captação de órgãos e tecidos.

Aos enfermeiros Solany Moreira e Vinícius Boaventura, parceiros de lutas e sonhos. 


\section{ABSTRACT}

Although legislation and the organ procurement teams for donation are composed by multiple professionals, the role of psychologists in these teams has not been reported in the literature. Purpose: to identify psychological aspects in the organ donation context and how the psychologist can act on the family approach process. Methods: This study comprises a review in the investigative review in the literature through bibliographic research within the 1997-2012 period from the descriptors: organ and tissue donation and procurement, health psychology, bioethics, death, mourning and intensive care unit. Studies found were categorized in 3 subsections: health psychology, the process of organ donation and psychological aspects involved in the donation and repercussions on the family approach. Conclusion: Health psychology has in its broad theoretical route practical conditions supporting the psychologist in the search to its inclusion in the organ procurement and donation, especially having their actions focused on the family acceptance and approach, and the subjective aspects in the process.

Keywords: Medication Adherence; Immunosuppressive Agents; Kidney Transplantation.

\section{REFERÊNCIAS}

1. Simonetti A. Manual de Psicologia Hospitalar: o mapa da doença. 1.ed. São Paulo: Casa do Psicólogo; 2004. P.14-6.

2. Nothen RR. A Doação de Órgãos no cenário da Unidade de Terapia Intensiva. São Paulo: Artmed/Panamericana; 2004. P. 14-48.

3. Gonçalves NRF, Ribeiro L. O papel do psicólogo no processo de doação de órgãos. Aroldo E, organizador. Tanatologia: temas impertinentes. Fortaleza: LC Gráfica e Editora; 2011. p. 225-34.

4. Resolução no 02/2001 CPF - Conselho Federal de Psicologia. [Internet]. Brasília, DF; 2001. [acesso em 2012 set 07]. Disponível em: www.cfp.org.br/wp-content/uploads/2006/01/ resolucao2001_2.pdf

5. Castro EK. Bornholdt E. Psicologia da Saúde x Psicologia Hospitalar: definições e possibilidades de inserção hospitalar. Psicol. cien. prof. 2004;24(3):48-57.

6. Chiattone HBC. A Significação da Psicologia no Contexto Hospitalar. Angerami-Camon VA, organizador. Vasconcellos EG, Gaspar KC, Chiattone HBC, Riechelmann JC, Sebastiani RW, editores. Psicologia da Saúde: um novo significado para a prática clínica. 2 ed. São Paulo: Cengage Learning; 2011.p.145-241.

7. Schmidt B, Gabarra LM, Gonçalves JR. Intervenção psicológica em terminalidade e morte: relato de experiência. Paidéia. 2011 setdez;21(50):423-30.

8. Lustosa MA. A Família do Paciente Internado. Rev SBPH. 2007 jun;10(1):3-8.

9. Teixeira RKC. Gonçalves TB. Silva JAC. A intenção de doar órgãos é influenciada pelo conhecimento populacional sobre morte encefálica? Rev Bras Ter Intensiva. 2012;24(3):258-62.

10. Brasil. Presidência da República, Casa Civil, Subchefia para Assuntos Jurídicos. Lei no 9434 de 04 de fevereiro de 1997. [Internet]. Brasília, DF; 1997. [acesso em 2012 set 07]. Disponível em : http://www.planalto.gov.br/ccivil_03/leis/I9434.htm

11. Brasil. Decreto nº 2268, de 30 de junho de 1997. [Internet]. Diário Oficial [da] República Federativa do Brasil. 1997 jun. 30 [acesso em 2012 set 07]. Disponível em: http://www.bioetica.ufrgs.br/dec2268.htm.

12. Silveira PVP, Silva AA, Oliveira ACS, Alves AJ, Quaresemin CR, Moraes $\mathrm{C}$, et al. Aspectos éticos da legislação de transplante $\mathrm{e}$ doação de órgãos no Brasil Revista Bioética. 2009; 17(1):61-75 [acesso em 2012 ago 27]. Disponível em: http://www.bioetica.cfm. org.br/index.php/revista_bioética/article/view/80/84 .
13. Brasil. Presidência da República, Casa Civil, Subchefia para Assuntos Jurídicos. Lei ${ }^{\circ} 10.211$ de 23 de março de 2001. Altera dispositivos da Lei no 9434, de 4 de fevereiro de 1997 [Internet]. Brasília, DF; 2011. [acesso em 2012 set 07]. Disponível em: http:// www.planalto.gov.br/ccivil_03/leis/leis_2011

14. ABTO. Registro Brasileiro de Transplantes. Dimensionamento dos Transplantes no Brasil e em cada estado (2005-2012). São Paulo; 2012. Ano XVIII(4). P. 23-5.

15. Conselho Federal de Medicina. Resolução CFM no 1.480/97. Brasília; 1997. [acesso em 2012 set. 15]. Disponível em: http:// ww.portalmedico.org.br/resolucoes/cfm/1997/1480_1997.htm.

16. Conselho Federal de Medicina. Resolução CFM no 1.826/2007. Brasília; 2007. [acesso em 2012 set. 15]. Disponível em: http://www. portalmedico.org.br/resolucoes/cfm/2007/1826_2007.htm.

17. Conselho Regional de Medicina do Estado de São Paulo. Processoconsulta CFM nº563/2000 PC/CFM/No42/2001. Diagnóstico de Morte Encefálica. Brasília; 2001. [acesso em 2012 set. 15]. Disponível em: http://www.portalmedico.org.br/pareceres/ CFM/2001/42_2001.htm.

18. Brasil. Ministério da Saúde. Portaria $n^{\circ} 2600$, de 21 de outubro de 2009. [Internet]. Brasília, DF; 2009. [acesso em 2012 out. 26]. Disponível em: http://www.brasilsus.com.br/legislacoes/ constituicao-federal/legislacoes/gm/ 101249-2600.html?q=

19. Brasil. Ministério da Saúde. Portaria no 2601, de 21 de outubro de 2009. [Internet]. Brasília, DF; 2009. [acesso em 2012 out. 26]. Disponível em: http://www.saude.mt.gov.br/upload/ legislacao/2601-[3015-120110-SES-MT]-pdf

20. Moraes, Bianca Nascimento. Perfil, crenças, sentimentos e atitudes de familiares doadores e não-doadores de órgãos [tese]. São Paulo: Faculdade de Medicina; 2009 [acesso 2012 out. 10]. Disponível em: http://www.teses.usp.br/teses/disponiveis/5/5131/tde-28082009-102356/

21. Groot J. Vernooij-Dassen M. Hoedemaekers C. Hoitsma A. Smeets W. Van Leeuwen E. Decision Making by Relatives About Brain Death Organ Donation: An Integrative Review. Transplantation. 2012; 12(93):1196-211.

22. Roza BA. Garcia VD. Barbosa SFF. Mendes KDS. Schirmer J. Doação de órgãos e tecidos: relação com o corpo em nossa sociedade. Acta Paul Enferm. 2010;23(3):417-22. 
23. Pessalacia JDR, Cortes VF, Ottoni A. Bioética e doação de órgãos no Brasil: aspectos éticos na aborgagem à família do potencial doador. Rev bioét. 2011;19(3):671-82.

24. Manuel A. Solberg S. Macdonald S. Organ donation experiences of family members. Nephrology Nursing Journal. 2010;37(3):22937.

25. Simpkin AL. Robertson LC. Barber VS. Young JD. Modifiable factors influencing relatives' decision to offer organ donation: systematic review. BMJ. 2009;339:b991.

26. Eckenrod EL. Psychological/Emotional Trauma of Donor Families. Transplantation Proceedings. 2008;40:1061-63.

27. Long T. Sque M. Addington-Hall J. Conflict rationalization: How family members cope with a diagnosis of brain stem death. Social Science\&Medicine, 2008;67:253-61.

28. Faria JG. Branco LM. Duarte PS. Miyazaki MCOS. Abbud-Filho M. Doação de órgãos para transplantes: informação e opinião de moradores do interior do estado de São Paulo. J Bras Transpl. 2007;10:752-55.
29. Guervós CS. Marinero PG. Estudo multicêntrico sobre negativas familiares a la donación. Grupo de Estudio sobre Negativas a la Donación. Coordinación de Trasplantes. Hospital General y Universitario de Alicante. [acesso 2012 set. 09]. Disponível em: http:// www.donacion.organos.ua.es/submenu2_2/articulo_negativas.asp

30. Morais TR. Morais MR. Doação de órgãos: é preciso educar para avançar. Saúde em Debate. 2012;95(36):633-39.

31. Radecki CM. Jaccard J. Psychological Aspects of Organ Donation: A Critical Review and Synthesis of Individual and Next-of-kin Donation Decisions. Health Psychology. 1997;16(2):183-95.

32. Cinque VM. Bianchi ERF. A tomada de decisão das famílias para a doação de órgãos. Cogitare Enferm. 2010; 15(1):69-73.

33. Rosel J, Ángel de Frutos M, Blanca MJ, Ruiz P. La decisión de donar órganos: variables contextuales y consecuencias de la decisión. Psicothema. 1995;7(3):605-18.

34. Mata JAF, Marcos MR, Guerrero RJG, Sánchez LL, Casado EG. Encuesta de Calidad Assistencial a Familias de Donantes tras la Experiencia de Donación. Medicrit. 2006;3(5):108-14. 